\title{
Prediction of Flap Necrosis by Using Indocyanine Green Videoangiography in Cases of Venous Occlusion in the Epigastric Flap Model of the Rat
}

\author{
Lucas M. Ritschl, MD, DMD ${ }^{1}$ Leonard H. Schmidt, MD ${ }^{1}$ Andreas M. Fichter, MD, DMD PhD ${ }^{1}$ \\ Alexander Hapfelmeier, $\mathrm{PhD}^{2}$ Anastasios Kanatas, MD, PhD, FRCS 3 \\ Klaus-Dietrich Wolff, MD, DDS, $\mathrm{PhD}^{1}$ Thomas Mücke, MD, DDS, $\mathrm{PhD}^{1,4}$
}

\footnotetext{
${ }^{1}$ Department of Oral and Maxillofacial Surgery, Klinikum rechts der Isar, Technische Universität München, München, Germany

2 Institute for Medical Informatics, Statistics and Epidemiology, Technische Universität München, München, Germany

${ }^{3}$ OMFS Department, Leeds Teaching Hospitals and St James Institute of Oncology, Leeds Dental Institute and Leeds General Infirmary, United Kingdom

${ }^{4}$ Department of Oral and Maxillofacial Surgery, Malteser Kliniken Rhein-Ruhr, Krefeld-Uerdingen, Germany
}

\begin{abstract}
Address for correspondence Lucas M. Ritschl, MD, DMD, Department of Oral and Maxillofacial Surgery, Klinikum rechts der Isar, Technische Universität München, Ismaningerstr. 22, D-81675 München, Germany (e-mail: lucas.ritschl@tum.de).
\end{abstract}

J Reconstr Microsurg Open 2018;3:e62-e69.

\begin{abstract}
\section{Keywords}

- venous congestion

- indocyanine green videoangiography

- prediction of flap necrosis

Background A compromised free flap perfusion attributable to vascular occlusion requires immediate operative correction. Indocyanine green (ICG) videoangiography may reduce the risk of partial skin flap necrosis in high-risk free flaps in patients undergoing head and neck reconstruction. The purpose of this study was to determine the role of ICG in cases of venous congestion in a rat model.

Methods A standardized epigastric flap was raised and repositioned in 35 rats. Full venous occlusion of the draining superficial inferior epigastric vein was temporarily applied for 4, 5, 6, or 7 hours. Blood flow measurements including simultaneous laserDoppler flowmetry and tissue spectrophotometry (oxygen-to-see [O2C]) and ICC videoangiography with the FLOW 800 tool were performed before flap raising, after temporary venous stasis, and after clinical monitoring for 1 week. The Youden index computed from the receiver operating characteristic curve was used to define an optimal cutoff value for necrosis prediction after 4 and 6 hours of stasis.

Results The ICG videoangiography with the FLOW 800 tool was found to be superior to $\mathrm{O} 2 \mathrm{C}$ in the prediction of flap necrosis. The accuracy of prediction was moderate after an interval of 4 hours of stasis (area under the curve [AUC] $=0.661 ; 95 \%$ confidence interval $[\mathrm{Cl}]$ : $0.489-0.834$ ) and good after 6 hours of stasis (AUC $=0.787 ; 95 \% \mathrm{Cl}$ : 0.65-0.915).

Conclusions The $\mathrm{O} 2 \mathrm{C}$ does not reliably predict tissue necrosis in cases of venous congestion. ICG videoangiography is a valuable tool that can predict clinical outcome and provide guidance on whether to salvage a congested flap.
\end{abstract}

received

February 5, 2018 accepted after revision August 30, 2018
DOI https://doi.org/

$10.1055 / \mathrm{s}-0038-1675408$. ISSN 2377-0813.
Copyright $\odot 2018$ by Thieme Medical Publishers, Inc., 333 Seventh Avenue, New York, NY 10001, USA Tel: +1(212) 584-4662.
License terms

(c) $(1) \risingdotseq$ 
If the viability of the skin paddle in a free flap cannot be reliably determined from clinical findings alone, ${ }^{1}$ an alternative objective method is essential to exclude vascular compromise. A plethora of specialized imaging modalities have been described to assess the adequacy of skin paddle perfusion of local and free flaps, pre-, intra-, and postoperatively. ${ }^{2-7}$ The use of indocyanine green (ICG) angiography can provide an early and accurate evaluation of flap perfusion. ${ }^{8,9}$ ICG angiography is not restricted to vascular assessment but includes ICG lymphography to improve sentinel lymph node mapping and lymphovenous bypass surgery. ${ }^{10}$ In the field of free flap surgery, the preoperative ICG angiography-assisted assessment of skin perfusion can help with flap design. Intraoperative evaluation allows an assessment of the patency of microvascular anastomosis. ${ }^{9,11}$ As stated consistently in the literature, the success of a free flap salvage operation is dependent on the early detection of vascular compromise and the subsequent short take-back time to the operating room. ${ }^{12}$ The most common reason for flap failure is venous congestion, and congested flaps are more prone to fail than arterially compromised flaps. ${ }^{1,13,14}$

Venous congestion has been previously addressed in several studies in various rat and rabbit models with the main focus on physiology and diverse treatments, including the effect of hemodilution or the use of low-molecularweight heparin on blood congestion. ${ }^{15,16}$ Nasser et al have described a significant reduction in limb blood flow in rats by using ICG angiography, if a stenosis of the femoral vein exceeded $85 \% .{ }^{17}$ However, as in most studies, the detection of acute blood flow changes and objective diagnostic results have not been correlated with long-term results and the potential prediction of the clinical course. The purpose of this study has been to compare two approved methods that might be used to predict flap necrosis and to determine valuable cutoff values for an objective assessment of results.

\section{Methods}

\section{Ethical Statement and Animal Welfare}

The study was compliant with current German regulations and guidelines for animal welfare and was approved by the local government (Regierung Oberbayern; AZ.: 55.2-1-54-2532-8515). Animals were housed in filter-top cages under hygienic conditions according to the guidelines of the Federation of European Laboratory Animal Science Associations. Water and standard rodent diet (Altromin; Altromin Spezialfutter GmbH \& Co. KG, Lage, Germany) were provided ad libitum. Rats were visited twice a day postoperatively (L.M.R. or L.H.S.), and all observations were performed according to a standardized protocol regarding animal welfare (pain reaction, animal's gestures, and behavior), wound healing of the abdomen, and movement.

\section{Workflow and Model Generation}

All procedures were performed under intravenous anesthesia (ketamine/xylazine) by using the femoral vein access on the right inguinal site after insertion of a microcatheter (Premicath; VYGON GmbH \& Co. KG, Aachen, Germany) and application of one-eighth doses of $10 \%$ ketamine when needed, as previously described in detail. ${ }^{18,19}$

A standardized $4 \times 4 \mathrm{~cm}$ epigastric flap on the left side was marked with a template, and a reference measurement (measurement no. 1) was performed by using simultaneous laser Doppler flowmetry and tissue spectrophotometry (O2C; LEA Medizintechnik GmbH, Giessen, Deutschland) and ICG videoangiography (INFRARED 800; Carl Zeiss Meditec AG, Oberkochen, Germany). The flap was raised leaving the superficial inferior epigastric artery and vein (SIEV) as the only vascular supply. ${ }^{20}$ Following this, the flap was sutured back with interrupted sutures (6-0 Ethilon; Ethicon, Norderstedt, Germany) leaving the caudal border open. Complete venous stasis was induced by applying a single Acland clip on the SIEV, the caudal border was temporarily closed, the microcatheter was removed, and the rats were roused from anesthesia for $4,5,6$, or 7 hours (each $n=7$ ). After the interval of full venous occlusion, $\mathrm{O} 2 \mathrm{C}$ analysis and ICG videoangiography were performed, and the temporary clip was removed under short anesthesia (measurement no. 2 ). Finally, the wounds were closed, and the rats were observed for 1 week. In the control group (no venous stasis), measurement no. 2 was performed after flap raising and repositioning to the corresponding wound bed.

After 1 week of observation, the rats were reanesthetized and each flap was documented photographically (500D Canon, Germany) before $02 \mathrm{C}$ and ICG videoangiography were performed once more (measurement no. 3, - Fig. 1). Images were planimetrically analyzed with regard to clinically vital and necrotic skin areas, and the necrotic area was measured by using NIH Image Software (Image 1.41o, National Institutes of Health, Madison/Wisconsin, United States). ${ }^{21}$

Subsequently, the rats were sacrificed under deep anesthesia with an intracardiac injection of pentobarbital at $60 \mathrm{mg} / \mathrm{kg}$ body weight (Narcoren; Fa. Rhone Merieux $\mathrm{GmbH}$, Laupheim, Germany) following a standard protocol. ${ }^{22}$

\section{Blood Flow Analyses}

The operation and ICG videoangiography were performed by using an operating microscope of the type OPMI Pentero integrated near-infrared videoangiography detection system with an integrated FLOW 800 tool (INFRARED 800; Carl Zeiss Meditec AG). ${ }^{7,23}$ The intraoperative ICG videoangiography of the epigastric flap was performed, as described in detail previously, by using weight-dependent intravenous injection of the ICG dye (ICG-PULSION; Pulsion Medical System AG, Munich, Germany). ${ }^{19,24}$ The ICG videoangiography was conducted at fivefold magnification. The emission signal of the ICG dye was detected, color coded with respect to fluorescence intensity for a period of 120 seconds with 25 images per second, and recorded as arbitrary units (AU) ${ }^{25}$ In the immediate analysis, two regions of interests (ROIs) were positioned in measurement nos. 1 to 3 according to the fluorescence staining behavior observed over time as described by Akita et al: one centrally located ROI = earlystaining area ( $<10$ seconds) and one at the right laterocranial border of the flap = delayed-staining area (10-60 seconds). ${ }^{26}$ In flaps with demarcated necrosis after 1 week, an 


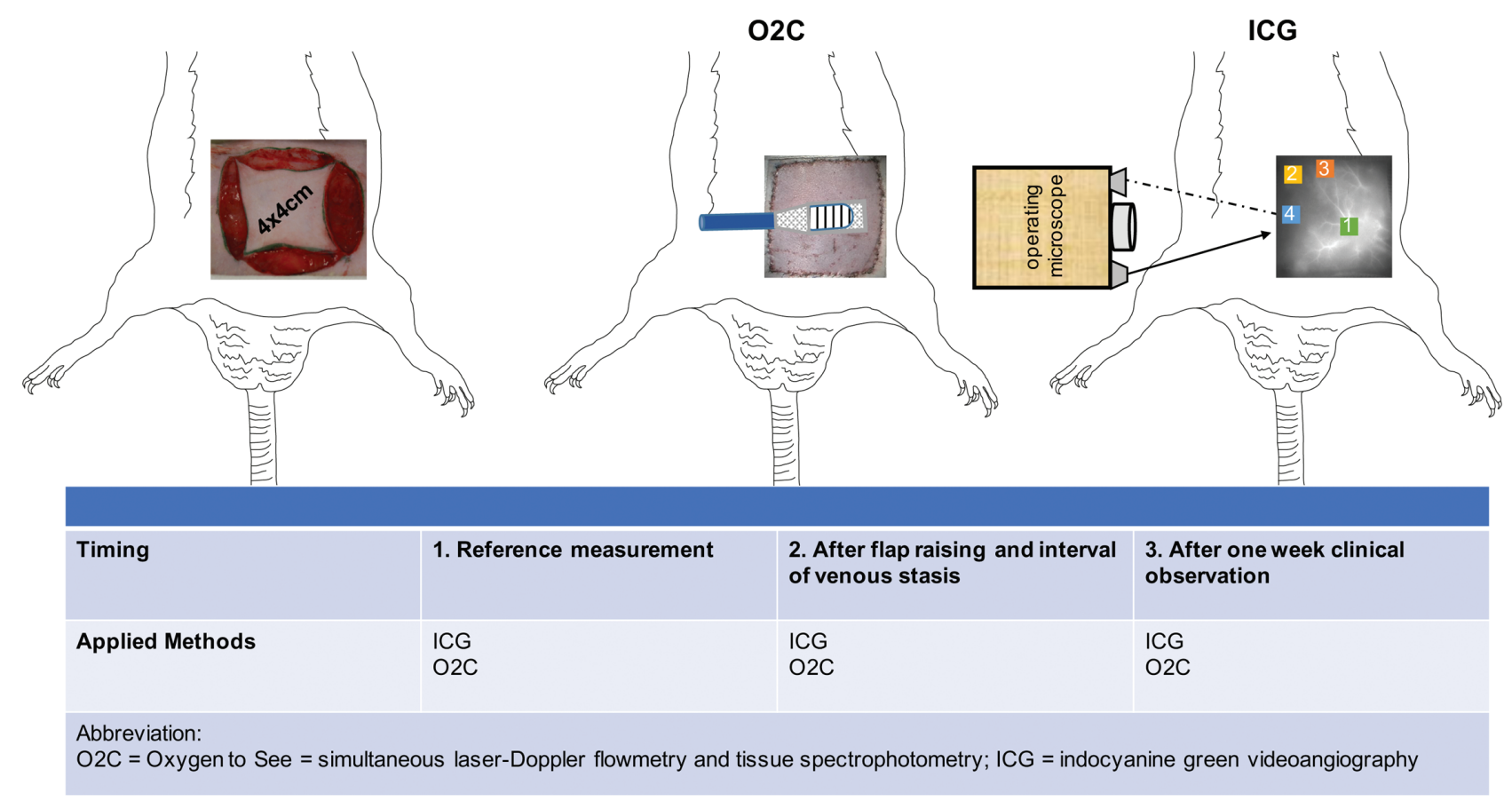

Fig. 1 Study workflow including the timing and the applied methods: simultaneous laser Doppler flowmetry and tissue spectrophotometry (O2C) and indocyanine green (ICG) videoangiography.

additional two ROIs were positioned in the area of necrosis for measurement no. 3 and retrospectively for measurement nos. 1 and 2. The values of the first maximum (first maximum) of the resulting curve and the area under the curve $\left(A U C^{\mathrm{ICG}}\right)$ for a time of 120 seconds were analyzed for all ICG measurements.

Simultaneous laser-Doppler flowmetry and tissue spectrophotometry (LEA Medizintechnik $\mathrm{GmbH}$ ) was performed with a centrally located probe on the flap as previously described. ${ }^{27}$ The probe was always located centrally to increase the reproducibility within the measurements for one and the same rat. The location of the probe is illustrated in - Fig. 1. The following parameters were registered: oxygen saturation $\left(\mathrm{SO}_{2}\right.$, in $\left.\mathrm{AU}\right)$, hemoglobin level ( $\mathrm{Hb}$, in $\mathrm{AU}$ ), velocity (velo, in $\mathrm{AU}$ ), and blood flow (flow, in AU). All parameters were measured simultaneously and noninvasively at the skin surface (S) and at a depth (D) of $8 \mathrm{~mm}$ in each $\mathrm{O} 2 \mathrm{C}$ measurement.

\section{Statistics}

The data were analyzed with IBM SPSS 23.0 for Windows software (IBM Corp., Armonk, NY). The distribution of the area of necrosis was found to be skewed by visual inspection and is therefore presented by the median and range. Accordingly, differences between the groups were evaluated by using the Mann-Whitney's $U$-test. The $p$-values are two sided and subject to a global significance level of 0.05. A conventional sample size was chosen in compliance with regulations of the local government on observational animal studies.

Receiver operating characteristic (ROC) curves and consecutive Youden indices were calculated ${ }^{28}$ to determine the discriminatory ability and to define the optimal cutoff values for the registered parameters in ICG videoangiography and
$\mathrm{O} 2 \mathrm{C}$ analysis to predict the incidence of necrosis. The status of the flap was assessed related to the ICG fluorescence intensity determined by the FLOW 800 tool. ${ }^{25}$ Sensitivity, specificity, and positive and negative predictive values for the prediction of necrosis were calculated from the relationship between the clinical appearance of the ROI and the results of the ICG fluorescence intensity at the corresponding ROI.

\section{Results}

\section{Flap Survival}

The incidence of necrosis increased with the time of venous stasis $(1 / 7,3 / 7,5 / 7,5 / 7$, and $6 / 7)$, as did the median necrotic area of flaps in the control group without venous stasis $(0.0$ $\mathrm{mm}^{2}$ range: $\left.0.00-100.06\right)$ and in subgroups with 4 hours $(0.0$ $\mathrm{mm}^{2}$ range: $\left.0.00-86.88\right), 5$ hours $\left(84.88 \mathrm{~mm}^{2}\right.$ range: $0.00-$ 263.24), 6 hours (133.16 $\mathrm{mm}^{2}$ range: $0.00-997.98$ ), and 7 hours (596.74 $\mathrm{mm}^{2}$ range: $0.00-1,005.82$ ) of venous stasis.

After an interval of 5 hours of venous stasis, the incidence and area of necrosis significantly increased compared with those of the control group $(p=0.037$ and $p=0.04$, respectively). All blood flow parameters measured with O2C or ICG videoangiography are shown in Appendices A and B.

\section{Receiver Operating Characteristic Curve and Cutoff Calculation}

The calculation of a ROC curve was not possible for the control group because no necrosis occurred at the area of the centrally localized probe.

The ROC curves for the $\mathrm{Hb} S$ and $\mathrm{D}$ parameters after 4 hours of venous stasis were associated with an AUC of 0.542 (95\% confidence interval (CI): 0.084-0.999) and 0.5 (95\% CI: 0.000-1.0), underlining poor accuracy (-Fig. 2). 

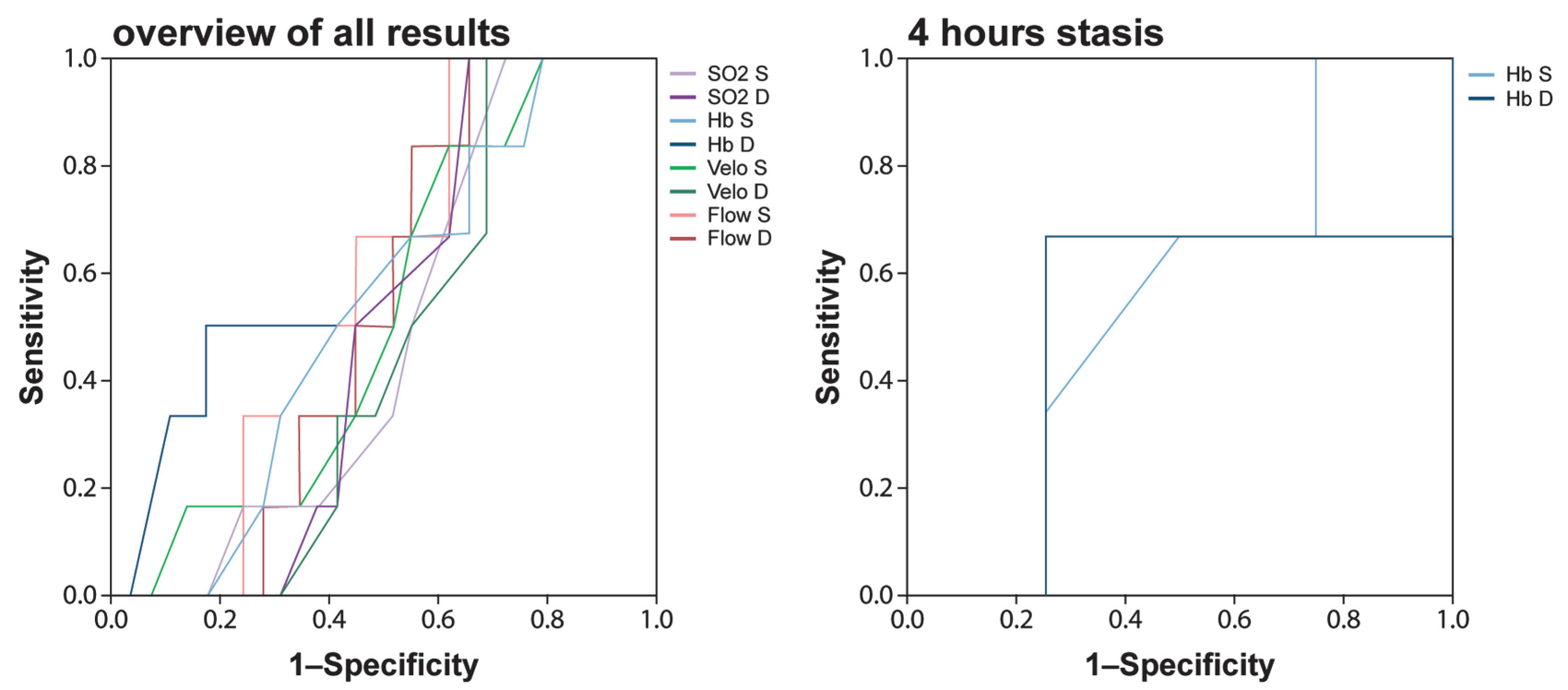

Fig. 2 Receiver operating characteristic (ROC) curves of all superficial (S) and deep (D) parameters of simultaneous laser Doppler flowmetry and tissue spectrophotometry (left side) and only hemoglobin S/D after 4 hours of venous stasis (right side). The area under the curve of hemoglobin S/D after 4 hours of venous stasis was only 0.542 and 0.500 , respectively.

According to the Youden index, the optimal cutoff value for $\mathrm{Hb} \mathrm{S}$ and $\mathrm{D}$ by using simultaneous laser-Doppler flowmetry and tissue analysis were $\geq 85 \mathrm{AU}$ and 141.5 for the prediction of flap necrosis (-Table $\mathbf{1}$ ).

The ROC curve for the first maximum and AUC ${ }^{\mathrm{ICG}}$ in the control group had an AUC of 0.865 (95\% CI: 0.679-1.0) and 0.942 (95\% CI: $0.853-1.0)$, underlining very good accuracy. The optimal cutoff values for the first maximum and AUC ${ }^{\mathrm{ICG}}$ of ICG videoangiography by using the FLOW 800 analysis were $\leq 37.8 \mathrm{AU}$ and 50,300 for the prediction of flap necrosis.

The ROC curve for the first maximum and AUC ${ }^{\mathrm{ICG}}$ after 4 hours of venous stasis had an AUC of 0.661 (95\% CI: 0.489-

Table 1 Receiver operating characteristic analysis of laserDoppler flowmetry and tissue spectrophotometry (O2C) for prediction of flap necrosis after venous occlusion for 4 hours

\begin{tabular}{|l|l|l|}
\hline \multirow{2}{*}{ Parameter } & \multicolumn{2}{|l|}{ 4 h stasis } \\
\cline { 2 - 3 } & Hb \\
\cline { 2 - 3 } & S & D \\
\hline AUC & 0.542 & 0.500 \\
\hline 95\% Cl & $0.084-0.999$ & $0.0-1.0$ \\
\hline Cutoff value (AU) & 85 & 141.5 \\
\hline Youden index & 0.25 & 0.417 \\
\hline Sensitivity (\%) & 100 & 66.7 \\
\hline Specificity (\%) & 25.0 & 75.0 \\
\hline PPV (\%) & 57.1 & 72.7 \\
\hline NPV (\%) & 100 & 69.3 \\
\hline
\end{tabular}

Abbreviations: AUC, area under the curve; $\mathrm{Cl}$, confidence interval; $\mathrm{D}$, deep; Hb, hemoglobin level; NPV, negative predictive value; $\mathrm{O} 2 \mathrm{C}$, oxygen-to-see; PPV, positive predictive value; ROC, receiver operating characteristic; $\mathrm{S}$, superficial; $\mathrm{SO}_{2}$, oxygen saturation.
0.834 ) and 0.659 (95\% CI: 0.482-0.835), underlining moderate accuracy. Corresponding optimal cutoff values for the first maximum and AUC ${ }^{\mathrm{ICG}}$ of ICG videoangiography by using the FLOW 800 analysis were $\leq 119.7$ and 88,131 . After 6 hours of venous stasis, the first maximum and $\mathrm{AUC}^{\mathrm{ICG}}$ had an AUC of 0.787 (95\% CI: 0.65-0.915) and 0.781 (95\% CI: 0.648-0.915), underlining good accuracy. Corresponding optimal cutoff values for the first maximum and AUC ${ }^{\mathrm{ICG}}$ of ICG videoangiography by using the FLOW 800 analysis were $\leq 45.2$ and 9,381 for the prediction of flap necrosis ( - Table 2 and - Fig. $\mathbf{3}$ ).

\section{Discussion}

The successful salvage of a venously congested free flap is dependent on correct detection and on a short time interval between the initial occlusion and the technically successful restoration of venous drainage. With regard to detection, postoperative routine clinical observations by medical staff on the intensive care unit, on the postanesthesia care unit, or on the regular ward for the first 72 hours represent the minimal level of care in centers for free flap transfer. ${ }^{1,29}$ For this purpose, various monitoring devices have been examined and have shown good results in the early detection of vascular compromise, especially by using $\mathrm{SO}_{2}$ or $\mathrm{Hb}$ values as the main indicator (in laser Doppler or tissue spectroscopybased methods). ${ }^{3,30}$ With ICG angiography, an additional monitoring tool has evolved that allows noninvasive effective monitoring able to detect vascular stenosis or to predict the incidence of necrosis in various ischemic models. ${ }^{17,24,25,31,32}$ However, no method has previously been used to predict the further clinical course of the flap, if the salvage operation is technically successful. Threshold values for none of the existing diagnostic methods in free flap failure have been described to facilitate the most difficult question in reconstructive microsurgery: will a technically 
Table 2 Receiver operating characteristic analysis of indocyanine green videoangiography for prediction of flap necrosis

\begin{tabular}{|l|l|l|l|l|l|l|}
\hline \multirow{2}{*}{ Parameter } & \multicolumn{2}{l}{ Control group } & \multicolumn{2}{l|}{ 4 h stasis } & \multicolumn{2}{l|}{ h stasis } \\
\cline { 2 - 7 } & First maximum & AUC & First maximum & AUC & First maximum & AUC \\
\hline ROC AUC & 0.865 & 0.942 & 0.661 & 0.659 & 0.787 & 0.781 \\
\hline $95 \%$ CI & $0.679-1.0$ & $0.853-1.0$ & $0.489-0.834$ & $0.482-0.835$ & $0.65-0.924$ & $0.648-0.915$ \\
\hline Cutoff value (AU) & 37.8 & 50,300 & 119.7 & 88,131 & 45.2 & 9,381 \\
\hline Youden index & 0.712 & 0.846 & 0.458 & 0.458 & 0.511 & 0.477 \\
\hline Sensitivity & $75 \%$ & $100 \%$ & $87.5 \%$ & $87.5 \%$ & $90.0 \%$ & $53.3 \%$ \\
\hline Specificity & $96.2 \%$ & $84.6 \%$ & $58.3 \%$ & $58.3 \%$ & $61.1 \%$ & $94.4 \%$ \\
\hline PPV & $95.2 \%$ & $39.4 \%$ & $67.7 \%$ & $67.7 \%$ & $69.8 \%$ & $90.5 \%$ \\
\hline NPV & $79.4 \%$ & $100 \%$ & $82.3 \%$ & $82.3 \%$ & $85.9 \%$ & $66.9 \%$ \\
\hline
\end{tabular}

Abbreviations: AUC, area under the curve; $\mathrm{Cl}$, confidence interval; NPV, negative predictive value; PPV, positive predictive value; ROC, receiver operating characteristic.
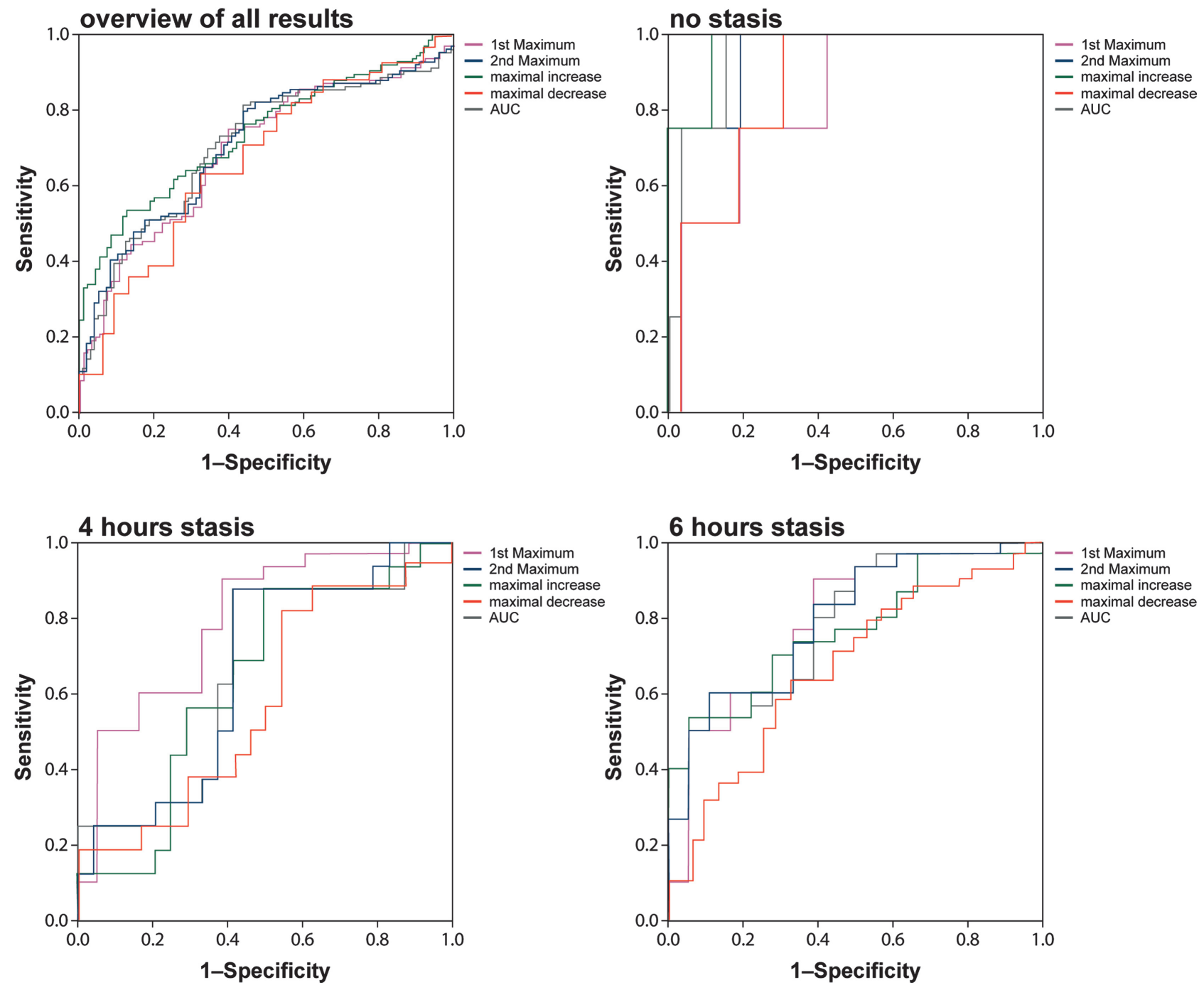

Fig. 3 Receiver operating characteristic (ROC) curves of indocyanine green videoangiography as an overview (top left), of the control group (top right), after 4 hours of venous stasis (bottom left), and after 6 hours of venous stasis (bottom right). The area under the curve of the first maximum after 4 and 6 hours of venous stasis were 0.661 and 0.787 , respectively. 
effective restoration of venous drainage also lead to a successful salvage and overall successful free flap transfer? Hence, we have compared two established methods with regard to the accuracy in the prediction of flap necrosis in flaps threatened by venous congestion, which is the most common postoperative complication.

Fourman et al described an earlier and more accurate prediction of flap survival by using ICG angiography in comparison with laser Doppler imaging in a modified McFarlane model of the rat. ${ }^{32}$ Munabi et al also obtained good results in predicting the incidence of necrosis following mastectomy by using ICG angiography. ${ }^{33}$

These positive findings correlate well with our previously reported results. ${ }^{24}$ However, in contrast to our presented study, venous congestion was not the focus of their study and Fourman et al and Munabi et al only performed a descriptive analysis of the prediction by using different threshold values for their monitoring tools. They did not determine a ROC curve to describe the accuracy of the defined thresholds or defined threshold values for their ICG angiography system. Akita et $\mathrm{al}^{26}$ combined intraoperative ICG angiography with regional tissue oximetry for postoperative flap monitoring. They intraoperatively categorized (early-, delayed-, or nostaining area) regions of flaps with respect to ICG dye staining behavior over time, but no thresholds were described. Furthermore, they correlated the areas with a calculated regional oxygen saturation $\left(\mathrm{SO}_{2}\right)$ index. Assuming that the incident regional $\mathrm{SO}_{2}$ index of less than 0.75 was a true positive for vascular compromise, the ROC curve revealed an AUC of 1.0 for the regional $\mathrm{SO}_{2}$ index, representing an ideal result of the test. The combination of the ICG angiography and tissue oximetry improved the accuracy of interpretation in postoperative free flap monitoring. However, the regional $\mathrm{SO}_{2}$ index was only used for general monitoring and the detection of the incidence of vascular compromise irrespective of the reason but not to predict the outcome of flap survival after a successful salvage operation.

To our knowledge, our study is the first to evaluate the predictive accuracy of ICG videoangiography using the FLOW 800 tool for the most common reason for free flap failure, namely, venous congestion. Our data indicate that good results are achievable regarding sensitivity, specificity, and positive and negative predictive values, but that the accuracy of our results are moderate until 6 hours of venous stasis (AUC in ROC curve: $>0.78$ ). Whereas at 4 hours of venous stasis, the predictability of flap necrosis was less accurate (AUC 0.661 for the first maximum) in comparison with 6 hours of venous stasis, ICG analysis at 4 hours still appeared to be superior to simultaneous laser-Doppler flowmetry and tissue spectrophotometry (AUC in ROC curve: 0.542 ). Four hours of venous stasis were associated with a small area of necrosis in the follow-up period and thereby seemed to be tolerated well by the fasciocutaneous flap as previously described by Harashina et al. ${ }^{34}$ Hence, the missing tolerance of flaps congested longer than 4 hours might also be reflected by the missing increase of $\mathrm{SO}_{2}$ in the 5- to 7-hour subgroups despite an increase in velocity and flow. This oppositional increase of velocity and flow might be due to opened shunts triggered by an intrinsic physiological reaction. Finally, the course results in a terminal breakdown of microcirculation and consecutive flap loss.

On the basis of our results, a moderate prediction of necrosis after 4 hours of venous stasis is both mandatory and feasible in the clinical setting. The knowledge of our findings might help facilitate the difficult decision as to whether to revise a congested but potentially salvageable free flap or to plan an alternative reconstruction when flap loss would be imminent, even if venous drainage was successfully restored. This could reduce futile salvage operations and reduce unnecessary procedures under anesthesia.

\section{Limitations}

The results are based on a fasciocutaneous flap in an animal model. Potential transfer to human beings is often controversial, and a one-to-one transfer is, therefore, inappropriate. Nevertheless, rats remain the gold standard in the field of microsurgical research and, during a time of recurrent ethical questions and surveys, preclinical studies still have to be performed.

The main disadvantage of ICG angiography is its cost, especially in the case of an integrated system in an operating microscope, as previously described by others. Nevertheless, in our opinion, the potential to decrease postoperative complications and to increase free flap salvage rates outweigh the acquisition costs. We only describe cutoff values for the OPMI Pentero integrated near-infrared videoangiography detection system with the integrated FLOW 800 tool (INFRARED 800; Carl Zeiss Meditec AG). For other systems, cutoff values may differ, but the application and ability of use of such systems are transferable. In contrast to laser Doppler flowmetry which allows continuous flap monitoring, ICG angiography can only be used intermittently. In this context, our study setup may differ from routine clinical use of laser Doppler flowmetry. However, the aim of this study was to assess the predictability of each method at a given time. Our study supports the body of evidence that laser Doppler flowmetry can only be interpreted in the context of continuous measurement and clinical evaluation. In our opinion, this is one of the greatest drawbacks of this technique since no valid cutoff values are known and the critical time point for successful flap salvage is often missed.

\section{Conclusions}

Fasciocutaneous flaps in the rat seem to withstand 4 hours of venous congestion providing that the vascular drainage is subsequently restored sufficiently. The use of the ICG angiography as a monitoring tool allows the prediction of flap necrosis after 6 hours of venous stasis at a highly accurate level and is moderately accurate even after 4 hours. Simultaneous laser-Doppler flowmetry and tissue spectrophotometry are not suitable for accurately predicting necrosis in cases of venous congestion in this animal model. The knowledge gained from our findings might help in difficult considerations as to whether a revision of a congested free flap is advisable.

Financial Disclosure

The authors have nothing to disclose. 


\section{Funding}

This work was supported by the German Research Foundation (DFG) and the Technical University of Munich within the funding programme Open Access Publishing.

\section{Acknowledgments}

All persons who have contributed to the study are listed as authors, since everyone has met the listed criteria for authorship.

\section{References}

1 Chen KT, Mardini S, Chuang DC, et al. Timing of presentation of the first signs of vascular compromise dictates the salvage outcome of free flap transfers. Plast Reconstr Surg 2007;120(01):187-195

2 Geis S, Klein S, Prantl L, Dolderer J, Lamby P, Jung EM. Quantitative assessment of free flap viability with CEUS using an integrated perfusion software. Handchir Mikrochir Plast Chir 2015;47(06): 389-395

3 Gimbel ML, Rollins MD, Fukaya E, Hopf HW. Monitoring partial and full venous outflow compromise in a rabbit skin flap model. Plast Reconstr Surg 2009;124(03):796-803

4 Hölzle F, Rau A, Loeffelbein DJ, Mücke T, Kesting MR, Wolff KD. Results of monitoring fasciocutaneous, myocutaneous, osteocutaneous and perforator flaps: 4-year experience with 166 cases. Int J Oral Maxillofac Surg 2010;39(01):21-28

5 Kempton SJ, Poore SO, Chen JT, Afifi AM. Free flap monitoring using an implantable anastomotic venous flow coupler: analysis of 119 consecutive abdominal-based free flaps for breast reconstruction. Microsurgery 2015;35(05):337-344

6 Holm C, Mayr M, Höfter E, Dornseifer U, Ninkovic M. Assessment of the patency of microvascular anastomoses using microscope-integrated near-infrared angiography: a preliminary study. Microsurgery 2009;29(07):509-514

7 Mücke T, Wolff KD, Wagenpfeil S, Hölzle F, Scholz M. Reliability of near-infrared angiography and micro-Doppler sonography for evaluating microvascular anastomoses. Plast Reconstr Surg 2010;126 (05):1506-1514

8 Liu DZ, Mathes DW, Zenn MR, Neligan PC. The application of indocyanine green fluorescence angiography in plastic surgery. J Reconstr Microsurg 2011;27(06):355-364

9 Beckler AD, Ezzat WH, Seth R, Nabili V, Blackwell KE. Assessment of fibula flap skin perfusion in patients undergoing oromandibular reconstruction: comparison of clinical findings, fluorescein, and indocyanine green angiography. JAMA Facial Plast Surg 2015; 17(06):422-426

10 Burnier P, Niddam J, Bosc R, Hersant B, Meningaud JP. Indocyanine green applications in plastic surgery: a review of the literature. J Plast Reconstr Aesthet Surg 2017;70(06):814-827

11 Hitier M, Cracowski JL, Hamou C, Righini C, Bettega G. Indocyanine green fluorescence angiography for free flap monitoring: a pilot study. J Craniomaxillofac Surg 2016;44(11):1833-1841

12 Mirzabeigi MN, Wang T, Kovach SJ, Taylor JA, Serletti JM, Wu LC. Free flap take-back following postoperative microvascular compromise: predicting salvage versus failure. Plast Reconstr Surg 2012;130(03):579-589

13 Hjortdal VE, Hansen ES, Hauge E. Myocutaneous flap ischemia: flow dynamics following venous and arterial obstruction. Plast Reconstr Surg 1992;89(06):1083-1091

14 Nguyen GK, Hwang BH, Zhang Y, et al. Novel biomarkers of arterial and venous ischemia in microvascular flaps. PLoS One 2013;8 (08):e71628

15 Kanayama K, Mineda K, Mashiko T, et al. Blood congestion can be rescued by hemodilution in a random-pattern skin flap. Plast Reconstr Surg 2017;139(02):365-374
16 Miyawaki T, Jackson IT, Elmazar H, et al. The effect of lowmolecular-weight heparin in the survival of a rabbit congested skin flap. Plast Reconstr Surg 2002;109(06):1994-1999

17 Nasser A, Fourman MS, Gersch RP, et al. Utilizing indocyanine green dye angiography to detect simulated flap venous congestion in a novel experimental rat model. J Reconstr Microsurg 2015;31(08):590-596

18 Ritschl LM, Fichter AM, Häberle S, et al. Ketamine-xylazine anesthesia in rats: intraperitoneal versus intravenous administration using a microsurgical femoral vein access. J Reconstr Microsurg 2015;31(05):343-347

19 Mücke T, Wolff C, von Düring M, Mitchell DA, Ritschl LM, Fichter AM. Form and size matter: increased risk of thrombosis in microvessels with surgically created endothelial lesions. J Reconstr Microsurg 2017;33(01):40-44

20 Strauch B, Murray DE. Transfer of composite graft with immediate suture anastomosis of its vascular pedicle measuring less than $1 \mathrm{~mm}$. in external diameter using microsurgical techniques. Plast Reconstr Surg 1967;40(04):325-329

21 Fichter AM, Borgmann A, Ritschl LM, et al. Perforator flaps-how many perforators are necessary to keep a flap alive? Br J Oral Maxillofac Surg 2014;52(05):432-437

22 Close B, Banister K, Baumans V, et al; DGXI of the European Commission. Recommendations for euthanasia of experimental animals: part 1. Lab Anim 1996;30(04):293-316

23 Raabe A, Beck J, Gerlach R, Zimmermann M, Seifert V. Nearinfrared indocyanine green video angiography: a new method for intraoperative assessment of vascular flow. Neurosurgery 2003;52(01):132-139, discussion 139

24 Mücke T, Fichter AM, Schmidt LH, Mitchell DA, Wolff KD, Ritschl LM. Indocyanine green videoangiography-assisted prediction of flap necrosis in the rat epigastric flap using the Flow ${ }^{\circledR} 800$ tool. Microsurgery 2017;37(03):235-242

25 Mücke T, Reeps C, Wolff KD, Mitchell DA, Fichter AM, Scholz M. Objective qualitative and quantitative assessment of blood flow with near-infrared angiography in microvascular anastomoses in the rat model. Microsurgery 2013;33(04):287-296

26 Akita S, Mitsukawa N, Tokumoto H, et al. Regional oxygen saturation index: a novel criterion for free flap assessment using tissue oximetry. Plast Reconstr Surg 2016;138(03):510e-518e

27 Mücke T, Rau A, Merezas A, et al. Identification of perioperative risk factor by laser-Doppler spectroscopy after free flap perfusion in the head and neck: a prospective clinical study. Microsurgery 2014;34(05):345-351

28 Youden WJ. Index for rating diagnostic tests. Cancer 1950;3(01): 32-35

29 Wolff KD, Hölzle F, Wysluch A, Mücke T, Kesting M. Incidence and time of intraoperative vascular complications in head and neck microsurgery. Microsurgery 2008;28(03):143-146

30 Hölzle F, Loeffelbein DJ, Nolte D, Wolff KD. Free flap monitoring using simultaneous non-invasive laser Doppler flowmetry and tissue spectrophotometry. J Craniomaxillofac Surg 2006;34(01):25-33

31 Russell JA, Conforti ML, Connor NP, Hartig GK. Cutaneous tissue flap viability following partial venous obstruction. Plast Reconstr Surg 2006;117(07):2259-2266, discussion 2267-2268

32 Fourman MS, Gersch RP, Phillips BT, et al. Comparison of laser Doppler and laser-assisted indocyanine green angiography prediction of flap survival in a novel modification of the McFarlane flap. Ann Plast Surg 2015;75(01):102-107

33 Munabi NC, Olorunnipa OB, Goltsman D, Rohde CH, Ascherman JA. The ability of intra-operative perfusion mapping with laserassisted indocyanine green angiography to predict mastectomy flap necrosis in breast reconstruction: a prospective trial. J Plast Reconstr Aesthet Surg 2014;67(04):449-455

34 Harashina T, Sawada Y, Watanabe S. The relationship between venous occlusion time in island flaps and flap survivals. Plast Reconstr Surg 1977;60(01):92-95 
Appendix A Descriptive statistics of simultaneous $\mathrm{O} 2 \mathrm{C}$ before flap raising and after various intervals of venous stasis of the superficial inferior epigastric vein

\begin{tabular}{|c|c|c|c|c|c|c|c|c|c|}
\hline \multirow[t]{2}{*}{ No. } & \multirow[t]{2}{*}{ (h) } & \multicolumn{2}{|c|}{$\begin{array}{l}\mathrm{SO}_{2} \\
\text { Median (min-max) }\end{array}$} & \multicolumn{2}{|c|}{$\begin{array}{l}\mathrm{Hb} \\
\text { Median (min-max) }\end{array}$} & \multicolumn{2}{|c|}{$\begin{array}{l}\text { Velo } \\
\text { Median (min-max) }\end{array}$} & \multicolumn{2}{|c|}{$\begin{array}{l}\text { Flow } \\
\text { Median (min-max) }\end{array}$} \\
\hline & & $\mathrm{s}$ & $\mathrm{D}$ & $\mathrm{s}$ & $\mathrm{D}$ & $\mathrm{s}$ & $\mathrm{D}$ & $s$ & $\mathrm{D}$ \\
\hline 1 & 1 & $35(3-56)$ & $60(35-74)$ & $69(52-83)$ & $40(32-50)$ & $19(11-58)$ & $29(18-54)$ & $93(38-489)$ & $153(88-308)$ \\
\hline \multirow[t]{5}{*}{2} & 0 & $7(1-16)$ & 55 (43-89) & $84(66-98)$ & $61(50-71)$ & $20(16-25)$ & $31(23-37)$ & $87(52-178)$ & $154(115-201)$ \\
\hline & 4 & $2(1-9)$ & $40(31-47)^{*}$ & $93(82-97)$ & $141(106-191)^{*}$ & $9(9-12)^{*}$ & $16(13-23)^{*}$ & $19(9-37)^{*}$ & $63(45-125)^{*}$ \\
\hline & 5 & $2(0-8)$ & $38(35-49)$ * & $93(89-100)$ & $137(126-151)^{*}$ & $12(10-18) * \S$ & $21(15-34)^{\S}$ & $40(17-71)^{*}$ & $114(68-194)^{\S}$ \\
\hline & 6 & $2(2-28)$ & $33(0-43)^{*}$ & $95(87-100)$ * & $140(83-166)^{*}$ & $15(8-20)^{* \S}$ & $29(25-49)^{\S}$ & $37(6-70)^{*}$ & $166(144-191)^{\S}$ \\
\hline & 7 & $4(2-7)$ & $37(0-41)^{*}$ & $95(87-98)^{*}$ & $152(121-166)^{*}$ & $13(9-15)^{* \S}$ & $23(22-29)^{* \S}$ & $29(4-68)^{*}$ & $129(107-152)^{\S}$ \\
\hline
\end{tabular}

Abbreviations: D, deep; Flow, blood flow; Hb, hemoglobin level; No. 1, reference measurement; No. 2, after flap raising and interval of venous stasis; $\mathrm{O} 2 \mathrm{C}$, laser Doppler flowmetry and tissue spectrophotometry; S, superficial; SD, standard deviation; $\mathrm{SO}_{2}$, oxygen saturation; Velo, velocity.

* Significant $(p<0.05)$ change compared with control group (no venous stasis).

${ }^{\S}$ Significant $(p<0.05)$ change compared with 4 hours stasis subgroup, each using Mann-Whitney's U-test.

Appendix B Analysis of ICG videoangiography before flap raising and after various intervals of venous stasis of the superficial inferior epigastric vein

\begin{tabular}{|c|c|c|c|c|c|c|c|}
\hline No. & $\begin{array}{l}\text { ROI } \\
\text { no. }\end{array}$ & (h) & $\begin{array}{l}\text { First maximum } \\
\text { median (min-max) }\end{array}$ & $\begin{array}{l}\text { Second maximum } \\
\text { median (min-max) }\end{array}$ & $\begin{array}{l}\text { Max. increase } \\
\text { median (min-max) }\end{array}$ & $\begin{array}{l}\text { Max. decrease } \\
\text { median (min-max) }\end{array}$ & $\mathrm{AUC}^{\mathrm{ICG}}$ median (min-max) \\
\hline \multirow[t]{4}{*}{1} & 1 & 1 & $157.7(58.6-332.8)$ & $164.9(67.2-306.3)$ & $0.03(0.01-0.13)$ & $-0.02(-0.05-[-0.01])$ & $131,064(52,438-250,468)$ \\
\hline & 2 & 1 & $102.8(38.7-187.9)$ & $106.5(40.4-224)$ & $0.03(0.01-0.09)$ & $-0.01(-0.14-[-0.003])$ & $88,209(33,308-183,554)$ \\
\hline & 3 & 1 & $118.1(30.6-280.4)$ & $126.9(30.9-254.4)$ & $0.03(0.01-0.09)$ & $-0.01(-0.04-[-0.003])$ & $101,489(25,205-193,194)$ \\
\hline & 4 & 1 & $127.9(27.9-261.6)$ & $123.8(28.3-248.9)$ & $0.03(0.01 .08)$ & $-0.02(-0.04-[-0.003])$ & $97,803(22,974-186,655)$ \\
\hline \multirow[t]{20}{*}{2} & \multirow[t]{5}{*}{1} & 0 & $72(37.9-164.3)$ & $84(44-183.5)$ & $0.04(0.02-0.3)$ & $-0.03(-0.07-[0.01])$ & $67,156(35,246-177,798)$ \\
\hline & & 4 & $17(9.8-248.4)$ & $16.7(9.4-247.8)$ & $0.02(0.01-0.69)$ & $-0.02(-0.04-[-0.01])$ & $14,253(2,088-238,814)$ \\
\hline & & 5 & $14.6(4.8-38.3)$ & $22.3(4.5-42.5)$ & $0.01(0.01-0.02)$ & $-0.01(-0.02-[-0.004])$ & $17,064(4,189-41,917)$ \\
\hline & & 6 & $19.6(3.3-47.7)$ & $19.8(5.6-53.1)$ & $0.01(0.01-0.02)$ & $-0.01(-0.02-[-0.01])$ & $11,369(4,113-35,055)$ \\
\hline & & 7 & $12.2(4.6-38.4)$ & $13.2(8.8-42.5)$ & $0.01(0.01-0.02)$ & $-0.01(-0.02-[-0.004])$ & $7,774(2,317-26,463)$ \\
\hline & \multirow[t]{5}{*}{2} & 0 & $65.8(5.2-84.9)$ & $77.8(8.9-95.5)$ & $0.05(0.01-0.2)$ & $-0.03(-0.09-[0.003])$ & $59,543(12,349-96,113)$ \\
\hline & & 4 & $11.2(5.8-143.1)$ & $11.1(4.5-138.8)$ & $0.01(0.01-0.59)$ & $-0.01(-0.04-[-0.01])$ & $6,010(1,079-132,034)$ \\
\hline & & 5 & $10.4(3.7-40.1)$ & $8.8(4.9-40.1)$ & $0.01(0.01-0.02)$ & $-0.01(-0.02-[0.005])$ & $6,276(2,713-40,153)$ \\
\hline & & 6 & $13.7(4.1-33.1)$ & $16.4(5.2-32.1)$ & $0.01(0.005-0.01)$ & $-0.007(-0-01-[-0.005])$ & $10,113(2,328-18,721)$ \\
\hline & & 7 & $11.4(4.8-16.7)$ & $13(4.6-24.3)$ & $0.01(0.01-0.02)$ & $-0.008(-0.01-[-0.005])$ & $7,242(1,522-17,128)$ \\
\hline & \multirow[t]{5}{*}{3} & 0 & 32.8 & 36.9 & 0.01 & -0.002 & 22,424 \\
\hline & & 4 & $5.9(5.1-38.8)$ & $5.4(4.3-35.2)$ & $0.02(0.01-0.02)$ & $-0.02(-0.02-[-0.01])$ & $657(0-26,056)$ \\
\hline & & 5 & $9.8(4.3-35.9)$ & $10.7(4.6-37.6)$ & $0.01(0.01-0.02)$ & $-0.01(-0.01-[0.004])$ & $6,409(2,285-24,149)$ \\
\hline & & 6 & $9.4(2.9-67.9)$ & $9.6(5.5-66.9)$ & $0.01(0.004-0.03)$ & $-0.01(-0.02-[-0.003])$ & $5,214(1,290-51,206)$ \\
\hline & & 7 & $5.5(0.7-9.1)$ & $4.6(0.5-8.7)$ & $0.01(0.005-0.01)$ & $-0.01(-0.01-[-0.004])$ & $1,469(0-5,274)$ \\
\hline & \multirow[t]{5}{*}{4} & 0 & 37.7 & 37.1 & 0.01 & $-0-009$ & 23,540 \\
\hline & & 4 & $14.9(4.2-48.8)$ & $14.1(3.4-45.9)$ & $0.01(0.01-0.02)$ & $-0.02(-0.02-[-0.01])$ & $8,003(0-34,359)$ \\
\hline & & 5 & $5.8(4.2-30.1)$ & $6.4(4.1-31.7)$ & $0.01(0.006-0.01)$ & $-0.01(-0.01-[-0.002])$ & $3,701(2,127-20,955)$ \\
\hline & & 6 & $9.3(1.1-32.1)$ & $10.3(1.7-31.9)$ & $0.01(0.01-0.02)$ & $-0.01(-0.01-[-0.003])$ & $2,369(119-22,209)$ \\
\hline & & 7 & $7.1(0.9-11.3)$ & $5.2(0.6-11.6)$ & $0.01(0.005-0.01)$ & $-0.01(-0.01-[-0.005])$ & $2,128(0-6,933)$ \\
\hline
\end{tabular}

Abbreviations: AUC, area under the curve; ICG, indocyanine green; No. 1, reference measurement; No. 2, after flap raising and interval of venous stasis (in 0 hour subgroup only one necrosis occurred corresponding with only one measurement in ROIs \#3 and 4); ROI, region of interest; SD, standard deviation. 